\title{
El SEÑORÍO ARZOBISPAL DE YEPES (SIGLOS XIII Y XIV)
}

\author{
Jorge Fernández Toribio ${ }^{1}$ \\ Universidad Complutense de Madrid
}

Recibido: 29 de abril de 2020

Aceptado: 7 de junio de 2020

\begin{abstract}
Resumen
El presente artículo tiene como finalidad contribuir a un mayor conocimiento acerca del señorío arzobispal de Yepes, así como de los diferentes agentes que intervinieron en su origen y posterior desarrollo. Su estudio para los siglos XIII y XIV resulta de gran interés pues nos permite conocer aspectos relacionados no sólo con el devenir de la villa y sus vasallos, sino también con el proceso de asentamiento previo por parte de las tropas cristianas en la región. No obstante, los enfrentamientos protagonizados por el concejo de Toledo y los prelados de la sede primada ocupan un espacio destacado dada su relevancia y el mayor volumen de datos al respecto.
\end{abstract}

\section{Palabras clave}

Toledo, jurisdicción, vasallos, señorío arzobispal y "repoblación".

\begin{abstract}
The aim of this article is to contribute to a broader learning of the archiepiscopal manor of Yepes and the different agents that took part in its origin and its subsequent development. Its study in the 13th and 14th centuries is of great interest as it allows us to identify not only the aspects related to the evolution of the town and the vassals but also those related to the settling process accomplished by Christians troops in the region. Nevertheless, the conflicts leaded by the council of Toledo and the prelates of the primacy see occupy an important place in this work due to their relevance and the large amount of data relate to them.
\end{abstract}

\section{Keywords}

Toledo, jurisdiction, vassals, archiepiscopal manor and "repopulation".

\section{Résumé}

Le présent article a pour objet de contribuer à une meilleure connaissance de la seigneurie archiépiscopale de Yepes, ainsi que des différents agents qui ont participé à sa fondation et à son développement ultérieur. Les XIIIe et le XIVe siècles constituent une période clef pour comprendre des aspects liés non seulement au devenir de la ville et de ses vassaux, mais aussi au processus d'établissement des troupes chrétiennes dans la région. Néanmoins, les affrontements entre le conseil de Tolède et les

1 Universidad Complutense de Madrid. Correo electrónico: jorfer09@ucm.es.

ORCID: https://orcid.org/0000-0002-6874-2209. 
prélats du siège primatial occupent une place importante dans ce travail en raison de leur impact et de la copieuse documentation que l'on conserve sur le sujet.

\section{Mots clés}

Tolède, juridiction, vassaux, seigneurie archiépiscopale, repeuplement.

\section{Introducción ${ }^{2}$}

El estudio de la historia de Yepes presenta para el período medieval una serie de interrogantes recurrentes en la bibliografía existente acerca del municipio toledano. El presente artículo tiene por objeto contribuir en cierto grado a la resolución del problema, aportando para ello datos y enfoques desconocidos hasta la fecha, sin dejar por ende de utilizar aquellos publicados con anterioridad por otros autores.

Tanto en el archivo municipal de la localidad como en el ubicado en la catedral de Toledo, se ha conservado un importante volumen de documentación relativa a la antigua villa arzobispal. Pese a ello, seguían siendo desconocidos una serie de aspectos de suma importancia de cara a abordar su estudio: ¿se encontraba despoblada la aldea cuando pasó a pertenecer a la mitra?, ¿el interés de los prelados por el lugar tuvo su origen en una donación regia?, ¿perdieron los titulares de la sede primada su señorío en la primera mitad del siglo XIV? y de ser así ¿cuándo y cómo se recupera? La respuesta a dichas incógnitas resultaba necesaria ante el propósito de ahondar en el conocimiento del papel ejercido por diversos agentes, externos e internos, en el origen y posterior desarrollo del señorío.

En relación a los segundos, y a modo de ejemplo, era prácticamente imposible calibrar en su justa medida la labor llevada a cabo por los prelados en el poblamiento de la zona. Asimismo, el estudio de su posible capacidad resolutiva ante los problemas adversos derivados del ejercicio de su papel como señores, presentaba trabas similares. Sin embargo éstas podían ser suplidas, en parte, con estudios relativos a enclaves eclesiásticos diferentes, recurso difícil de aplicar a otros protagonistas. Sólo con la confirmación de una continuidad en el poblamiento de Yepes, desde al menos mediados del siglo XII, se podría lograr una mayor aproximación acerca de los que pasarían a convertirse en nuevos vasallos de los titulares de la sede primada. Ello nos capacitaría para iniciar el planteamiento de nuevos interrogantes: ¿los vecinos del lugar presentaron una respuesta colectiva ante las pretensiones de la Iglesia?, ¿hubo algún tipo de conflicto derivado de la nueva situación?

En cuanto al conocimiento del papel ejercido por los que podrían denominarse agentes externos, éste presentaba prácticamente los mismos inconvenientes. Mientras que las posibles lagunas concernientes a las relaciones trazadas entre la monarquía y la Iglesia

2 Las abreviaturas presentes en el artículo hacen referencia al Archivo Municipal de Toledo (AMT), al Archivo Municipal de Yepes (AMY), al Archivo Capitular de Toledo (ACT) y a la Biblioteca Nacional de España (BNE). 
en relación al señorío podían solventarse a través del estudio de su contexto, dicha solución resultaba más difícil de aplicar en lo tocante al concejo de Toledo. Era necesario determinar el origen de las propiedades ubicadas en Yepes en poder de los toledanos para, posteriormente, analizar las posibles estrategias llevadas a cabo por los diferentes arzobispos con el fin de proteger sus derechos señoriales.

\section{La conversión de una aldea concejil en villa arzobispal}

En opinión de algunos autores ${ }^{3}$ Yepes constituiría ya en época islámica un enclave fortificado, debiendo caer en poder cristiano como consecuencia de la toma de Toledo. De ser así no debió de gozar de gran relevancia, defensiva o estratégica, pues las menciones a la misma en el contexto de las luchas protagonizadas por castellanoleoneses y almorávides son nulas ${ }^{4}$. Oreja, recuperada por los musulmanes en el año 1113, se convertiría en una base óptima desde la que hostigar a la ciudad de Toledo. Sin embargo la ruta predilecta escogida para ello en la región parece ir pareja a la ribera de los ríos Algodor y Tajo donde, en contraposición al lugar objeto de nuestro estudio, sí encontramos enclaves como Aceca. El importante valor de la misma para ambos bandos tiene un consecuente reflejo en las fuentes medievales ${ }^{6}$.

Trascurrida una década desde la toma definitiva de Oreja por parte de los cristianos, acaecida en el año 1139, tiene inicio la reorganización del espacio situado entre ésta y la ciudad de Toledo. Con dicho fin el rey llevará a cabo una larga serie de concesiones dirigidas a incentivar la reactivación económica y el poblamiento del espacio a la vez que garantizar su defensa ${ }^{7}$. En este contexto debió de producirse el primer desarrollo importante experimentado por las aldeas aledañas de «Hepes» y «Fontes», ambas integradas en el alfoz toledano ${ }^{8}$. La segunda, calificada en un principio como villa, sería entregada por el monarca en el año 1151 a diez personas. Los propietarios podrían disponer de ella a su voluntad y legarla a sus hijos, debiendo pechar una cuantía determinada de sueldos ${ }^{9}$ La donación no debió de ser del todo fructífera pues a comienzos del siglo

\footnotetext{
Pavón Maldonado, “Miscelánea de arte...”, p. 221; Merlos Romero, “Arquitectura militar...”, p. 36.

4 En los Anales Toledanos encontramos la mención a pequeñas aldeas cercanas a Toledo atacadas por los almorávides. Entre los nombres de las mismas no aparece reflejado el de Yepes. FlóRez, España Sagrada, pp. 381-423.

5 Los ataques dirigidos contra la ciudad de Toledo en 1109, 1130 y 1139 conllevaron el ataque de Aceca. González González, Repoblación de Castilla..., pp. 101, 136 y 143.

6 Vid. Díaz Fernández, “Aceca...”, pp. 81-96; GonzÁlez GonzÁlez, Repoblación de Castilla..., pp. 203; Muñoz Ruano, Construcciones histórico militares..., pp. 490-501.

7 JimÉnEZ de Gregorio, "La comarca...”, pp. 19-20.

8 En 1210 se indica así. GonzÁlez Palencia, Los mozárabes..., doc. nº 380b. Para una mayor comprensión del espacio geográfico al que aludimos véase el mapa presente al final del artículo.

9 Hernández, Los Cartularios..., doc. nº 82. González Palencia difiere en la fecha de la cesión indicando por contra el año 1145. Gonzélez Palencia, Los mozárabes..., p. 193.
} 
XIII la antigua villa figura ya como una simple alquería perteneciente a la aldea vecina ${ }^{10}$, quedando anexionada y eclipsada por ésta.

Yepes había sido concedida por Alfonso VII en una fecha desconocida"1 a la parroquia toledana de San Nicolás, quien consecuentemente debió de organizar la división del lugar y de sus tierras en «partes» y «suertes»"12 a entregar entre los vecinos que en aquella época habitaban la collación. Los términos «pars y «sors» constituyen una clara reminiscencia de los modelos de propiedad y explotación vigentes en el Bajo Imperio Romano. Ambos hacen alusión en última instancia a una «participación individual en su conjunto» ${ }^{13}$. Su uso indistinto parece estar constatado incluso en época carolingia ${ }^{14}$, algo que sin embargo no ocurre en la mayor parte de la documentación traducida del árabe por González Palencia, donde se observa una clara diferenciación. Ello nos podría estar indicando una evolución en el lenguaje tendente a una mayor especificidad a la hora describir el objeto sobre el que recaería la participación: las tierras a cultivar (suertes) $)^{15} \mathrm{y}$ los derechos adjuntos a la propiedad (partes) ${ }^{16}$.

Sirviéndonos de dicho planteamiento, podemos intentar suponer cómo pudo ser el proceso de ocupación de Yepes a mediados del siglo XII. En primer lugar la parroquia debió de realizar una clasificación de las diferentes tierras de cultivo presentes en la aldea, diferenciando aquellas que a su llegada ya se encontraban siendo trabajadas de las que por contra serían aptas para ello en un futuro. Las segundas serían entregadas a los vecinos de la collación para su plantación ${ }^{17}$ tras ser numeradas ${ }^{18}$ y "sorteadas". En cuanto a las primeras, la propiedad de las mismas sería arrebatada a sus propietarios, quienes en el supuesto de querer seguir disfrutando de su uso se verían obligados a

10 Yepes. González Palencia, Los mozárabes..., docs. no 407 y 1123.

11 Se tiene constancia de la entrega de Yepes al «concejo» de San Nicolás únicamente por la mención que de ello se hace en la partición de términos efectuada en 1215 entre la aldea toledana y Ocaña. HerNÁndez, Los Cartularios..., doc. $\mathrm{n}^{\circ}$ 360. González Palencia considera en su obra la posibilidad de que se llevara a cabo una entrega conjunta de Yepes y Fuentes, datándola en el año 1145. GonzÁlez Palencia, Los mozárabes..., p. 193. La donación de diferentes aldeas a las collaciones de San Miguel y San Vicente en el año 1150 por parte del rey puede ayudarnos a datar la de Yepes. GonzÁlez Palencia, Los mozárabes..., p. 93; GonzÁlez GonzÁlez, Repoblación de Castilla..., p. 217.

12 Ello se advierte de la lectura de una serie de escrituras fechadas en 1210, 1213, 1214 y 1215. GonZÁLeZ Palencia, Los mozárabes..., docs. no 380b, 407, 424, 748, 749, 750, 753 y 1123.

13 García Moreno, "El término «sors» y otros...», p. 149.

14 IBIDEM, p. 50.

15 Se han conservado escrituras de compraventa fechadas en 1210, 1245 y 1248, que afectan a Yepes y Villasequilla, en las que son mencionadas específicamente suertes «de tierra», algunas de ellas compuestas por corrales, chozas, sembradura, barbecho, bueyes y aperos. GonzÁlez Palencia, Los mozárabes..., docs. $\mathrm{n}^{\mathrm{o}} 576,599,600$ y 1123 .

16 No sólo al uso de los espacios comunales sino también a la posible percepción de ingresos procedentes de la explotación de los bienes arrebatados a los antiguos habitantes del enclave. Hecho no constatable documentalmente pero probable al ser las citadas partes objeto de recurrentes transacciones económicas. 17 Uno de los herederos de los parroquianos afirma que su padre adquirió sus posesiones en Yepes «por derecho de plantación». González Palencia, Los mozárabes..., doc. 408.

18 De las suertes pertenecientes a la cercana Villaseca de Valdecarábanos se afirma que fueron «enumeradas en la lista del Emperador cuando repartió esta alquería». GonzÁlez Palencia, Los mozárabes..., doc. $\mathrm{n}^{\circ} 566$. 
pagar un tributo. La recaudación obtenida a través del mismo sería distribuida entre los beneficiarios de las partes en que se dividía la propiedad de la aldea.

Un determinado porcentaje de estas partes, a raíz de la muerte de sus titulares, podía acabar en poder de personas ajenas a la collación. En respuesta a ello la parroquia pudo establecer el pago del mortuorio. Nos encontramos ante un impuesto que gravaba los bienes de las personas que acababan de fallecer, siendo cobrado en la mayoría de los casos por las parroquias al suponer éstas que el difunto pudiera haberles defraudado alguna cuantía, u ocasionado alguna pérdida si nos atenemos al caso que nos ocupa ${ }^{19}$. De este modo cuando en 1213 el rey concede al arzobispo de Toledo el «mortuariu» de Yepes y Fuente ${ }^{20}$ le está arrebatando en cierto grado a la collación toledana la propiedad de las mismas ${ }^{21}$.

Fuentes debió de experimentar un proceso similar al descrito tras ser anexionada al dominio parroquial, sin embargo, los beneficiarios de la donación regia del año 1151 no parecen perder la propiedad de las tierras que explotaban ${ }^{22}$. Al menos ello se advierte de la lectura de dos documentos en los que los herederos de estos primeros pobladores venden su herencia. En 1225 la hija de Pedro Alforcén hace entrega al arzobispo de Toledo de las suertes que había heredado, a cambio de 50 maravedíes $^{23}$. Unos 15 años antes el hijo de Pelayo Godínez, ballestero del rey, también opta por desprenderse de la parte que había heredado, obtenida por su padre al ser vecino de San Nicolás ${ }^{24}$.

También se ha planteado la posibilidad de que el término mortuorio fuera utilizado en el citado documento como sinónimo de muerto o yermo, habiendo donado el rey dos despoblados al arzobispo ${ }^{25}$. Algunos documentos elaborados en años previos y posteriores a la concesión regia parecen demostrar lo contrario. En 1210 Micael y su padre Martín Micael, ambos propietarios en las aldeas que nos ocupan, inician una serie de transacciones económicas dirigidas aparentemente a hacerse con el control de las mismas $^{26}$. Llevaron a cabo la compra de cinco partes tan solo por 3 mizcales, precio que estaría indicándonos que los vendedores únicamente se estaban desprendiendo de sus derechos ${ }^{27}$. Ese mismo año lograrían asimismo que les fueran donadas tres suertes,

\footnotetext{
19 Conde de Cedillo, Contribuciones e impuestos..., p. 210. El cobro del impuesto en Toledo está constatado en 1266, año en que Alfonso Mateos afirma en su testamento que pagará el mizcal mortuorum. GonzÁlez Palencia, Los mozárabes..., doc. 1030.

20 García Luján, Privilegios reales..., doc. no 43.

21 No así a sus vecinos, quienes seguirían esgrimiendo su derecho a poseer una parte de la propiedad.

22 Martín Muñoz, Pelayo Godínez, Pedreion, Gonzalo Jiménez, Pedro y Domingo Peidrez, Cehal, Martín Garcíez, Muño Garcíez y Pedro Alforcén. Hernández, Los Cartularios..., doc. no 82.

23 Hernández, Los Cartularios..., doc. $\mathrm{n}^{\circ} 416$.

24 González Palencia, Los mozárabes..., doc. nº 380b.

25 Merlos Romero, Yepes en la Edad Media..., p. 48. Molénat se cuestiona ya este repentino declive. Molénat, Campagnes et monts..., p. 107.

26 González Palencia, Los mozárabes..., docs. no $380 \mathrm{~b}$ y 1123

27 En 1214 una heredad en Yepes es permutada por una viña tasada en 20 mizcales de oro, precio muy superior al medio mizcal y un mizcal. Ello reforzaría la hipótesis del diferente significado de suertes y partes. GonzÁlez Palencia, Los mozárabes..., doc. $\mathrm{n}^{\circ}$ 406. De haber existido una campaña militar en la zona que hubiera asolado los cultivos entiendo que la destrucción hubiera sido generalizada. Por otra parte,
} 
una parte y todo lo que dos hermanos habían heredado de su padre. No parece existir parentesco alguno entre donantes y receptor por lo que tales entregas podrían ir ligadas al interés de evadir el pago del impuesto parroquial.

En estas fechas padre e hijo no fueron los únicos en mostrar interés por los enclaves que nos ocupan, Orabuena lleva a cabo en 1212 una venta en favor del alguacil de Toledo Gonzalo Facundo. La presencia de dicha escritura en los archivos calatravos puede indicarnos una posterior adquisición de la parte por la Orden ${ }^{28}$. Sin embargo todas estas empresas resultarían vanas ante el creciente interés mostrado por el titular de la sede primada.

Transcurridos tan solo dos años desde su elección, Rodrigo Jiménez de Rada inicia un largo proceso dirigido a adquirir la mayoría de las partes en que se dividía la propiedad de algunas aldeas pertenecientes al alfoz toledano. A modo de ejemplo citaremos Villamuelas y Villaseca de Valdecarábanos ${ }^{29}$, aunque el verdadero logro de la Iglesia en la región que nos ocupa, la obtención de La Guardia, se deba a una donación regia ${ }^{30}$. En marzo del año 1213 el prelado consiguió comprar al abad de Santo Domingo de Silos el enclave de Cabañas ${ }^{31}$, a escasos kilómetros de Yepes y Fuentes. En estas últimas, un mes más tarde seis personas donarían «todo lo que poseían» al arzobispo ${ }^{32}$, quien igualmente obtendría de otras seis todo «lo que les pertenecía en ellas». La diferenciación hecha en el mismo documento entre los dos grupos podría reforzar la hipótesis de la existencia de tres tipos de donaciones: de tierras (suertes), de derechos (partes) y de ambas. En favor de ello contamos con una nueva transacción en la que una familia entrega únicamente sus «derechos» ${ }^{33}$. Algunos de los donantes pertenecían a importantes familias afincadas en Toledo, es el caso de Alfonso Estébanez, hijo del alguacil y alcalde de la ciudad Esteban Illán ${ }^{34}$.

La concesión del mortuorio tendría lugar unas semanas más tarde, de modo que no podemos vincular las primeras donaciones a una repentina subida del impuesto, medida que sin duda habría forzado a parte de la población a desprenderse de sus derechos. Éstos siguieron siendo esgrimidos por algunos propietarios, razón por la que el prelado todavía no podría disponer libremente de las aldeas. La única opción que le restaba con el fin de lograrlo sería la compra de la totalidad o la mayoría de las partes en que se dividía la propiedad de los citados enclaves, necesidad que bien pudo ser aprovechada

\footnotetext{
no podían existir suertes sin cultivar pues uno de los herederos en Yepes alega que su padre recibió lo que tenía en el lugar por derecho de plantación. González Palencia, Los mozárabes..., doc. n 408.

28 Rodríguez-Picavea, "Documentos para el estudio...", doc. nº 647.

29 Grassotti, Don Rodrigo..., p. 92.

30 Producida entre los años 1211 y 1213. Fita Colomé, "La Guardia...”, p. 378.

31 Hernández, Los Cartularios..., doc. no 330.

32 González Palencia, Los mozárabes..., doc. no 748. Estas seis personas realizan la donación sin haber obtenido previamente el consentimiento de sus familiares, comprometiéndose a conseguirlo. Ello llevó a Hilda Grassotti a plantear una posible cesión forzosa. Grassotti, Don Rodrigo..., p. 88. Ese mismo mes dos nuevas personas donarían todo lo que les pertenecía. González Palencia, Los mozárabes..., doc. $n^{\circ} 749$.

33 González Palencia, Los mozárabes..., doc. no 750.

34 Sobre las genealogías de los linajes presentes en Yepes ver: MolénAt, Campagnes et monts..., p. 107.
} 
por algunas personas. En 1214 uno de los criados de Rodrigo Jiménez de Rada, llamado Domingo Pascual, compra para éste a Martín Micael 14 partes y suertes por el precio de 300 mizcales de oro. Desconocemos el origen de 5 de ellas, sin embargo, de las otras 9 sabemos que 4 habían sido donadas a Martín y 5 las había comprado por 3 mizcales $^{35}$. Por mucho que le valieran las 5 suertes restantes el beneficio que debió de lograr el hijo del alguacil de Toledo Micael Domínguez en cuatro años es realmente notorio, aun teniendo en cuenta la crisis que tuvo lugar el año anterior. Posteriormente, en fechas cercanas, únicamente se constatan una donación y dos ventas más ${ }^{36}$.

Pese al paso de los años no todos los herederos debieron de estar dispuestos a vender sus derechos. Cuando en el año 1215 hubieron de trazarse los límites entre Yepes y Ocaña, acudieron como representantes de la primera no sólo el alcalde y los «omnes buenos» de Toledo, acompañados de algunos hombres del arzobispo, sino también los «omnes que dizen que eran herederos en Yepes» ${ }^{37}$. A pesar de ello Rodrigo Jiménez de Rada se consideraría ya propietario del enclave, logrando que sus nuevas adquisiciones fueran confirmadas por el Papa Honorio III en el mes de febrero del año 1217 $7^{38}$. Desde entonces la antigua aldea toledana debió de quedar integrada oficialmente en la mesa arzobispal tras una larga y difícil empresa ${ }^{39}$.

En el contexto de una política dirigida a fomentar el desarrollo económico y el poblamiento de las tierras de la Iglesia, el arzobispo concede en 1223 una serie de cartas forales. Algunos de los beneficiarios fueron los vecinos de San Justo, las aldeas de Alcalá, Talamanca, Brihuega y Yepes ${ }^{40}$. Transcurridos diez años desde la concesión del mortuorio y seis desde la obtención de la mencionada confirmación papal, la antigua aldea pasó a convertirse en villa arzobispal, produciéndose su segregación jurídico-administrativa respecto al concejo de Toledo. Nos encontramos por tanto ante la transformación de un señorío" foncière" en otro banal ${ }^{41}$.

A diferencia del resto de los fueros otorgados, vinculados con el entregado a Ávila ${ }^{42}$, el de Yepes posee una adscripción diferente ${ }^{43}$. Su semejanza con el concedido por la

\footnotetext{
GonzÁlez Palencia, Los mozárabes..., doc. no 407.

6 Ibídem, docs. $n^{\circ}$ 408, 424 y 753.

37 Hernández, Los Cartularios..., doc. no 360 .

38 Yepes y Cabañas aparecen entre las posesiones que el Papa confirma al arzobispo. ACT I.12.A.1.5; Fita Colomé, "La Guardia...", p. 382; Mansilla, La documentación..., doc. no 31.

39 Por ello destaca que el prelado llegara a plantearse en 1238 donar las rentas procedentes de Yepes al cabildo, junto con las de otros 13 enclaves. El fin de las mismas habría sido la dotación de 20 capellanías y la celebración de aniversarios en su nombre, el de sus padres y el del rey. Tal decisión finalmente no tendría lugar. Hernández, Los Cartularios..., doc. $\mathrm{n}^{\circ} 450$.

40 A las que parece unirse, entre otras, Cazorla. Grassotti, Don Rodrigo..., p. 50-53.

41 Molénat establece una clara distinción entre ambos tipos, demostrando que la jurisdicción en las posesiones arzobispales de Camarena, Canales y Añover, al contrario de lo ocurrido en Yepes, era ejercida por el concejo de Toledo. Molénat, Campagnes et monts..., p. 408-410.

42 San Justo, las aldeas de Alcalá, Talamanca y Brihuega. Barrero García y Alonso Martín, Textos de derecho..., p. 553.

43 El documento original conservado en el Archivo Municipal de Yepes se encuentra muy afectado por la humedad, siendo prácticamente ilegible. AMY, perg. $\mathrm{n}^{\circ} 1$. Su contenido lo conocemos hoy día gracias a
} 
Orden de Calatrava a la vecina Huerta de Valdecarábanos, en el año 1204, ya ha sido señalada con anterioridad por María Magdalena Merlos en su obra ${ }^{44}$.

Los aspectos por destacar del documento que centra nuestro interés son abundantes ${ }^{45}$. De todos ellos cabe mencionar en primer lugar la aparente elevada participación de los vecinos en el gobierno de la población, por ellos y de entre ellos, con la anuencia de los alcaldes, serían designados anualmente el juez y los nuevos alcaldes del lugar: «concilium cum alcaldibus ponat iudicem et alcaldes, et nemo habeat alcaldiam vel iudicatum nisi per unum annum, et isti sint ex vicinis» ${ }^{46}$.

En algunas villas bajo señorío episcopal el deseo de participar en el nombramiento de los cargos municipales por parte de los vasallos derivó en serios enfrentamientos, ocasionando incluso la intervención del monarca ${ }^{47}$. Ello nos lleva a pensar en que el arzobispo Rodrigo quizás no renunciara del todo a intervenir en el gobierno municipal, siendo nombrados por él los dos primeros alcaldes.

El control económico que el señor ejercía sobre la villa queda en cambio reflejado con mayor claridad. Reservó para sí la tenencia de una serie de tiendas a alquilar y estableció una serie de tributos tanto en el horno de «poia» como en carnicerías. De cada 20 panes que se cocieran, uno debería de ser entregado. En cuanto a la venta de carne, se exigió una cantidad de libras preestablecidas por todo animal que se lograra vender: «de baca octo libras, de capro octo libras, de cabra sex libras, de carnero una libra, de obeja una libra, de cabrone una libra, de cabrito una libra, de cordero una libra $\left.{ }^{48}\right\rangle$.

Otra serie de disposiciones se encuentran dirigidas a atraer población. Mientras que la mayor parte de los vecinos debían de pagar al prelado un impuesto anual de «medios morabedinos» a entregar en la festividad de San Miguel, los nuevos pobladores estarían exentos de ello durante los tres primeros años. Durante ese tiempo su situación se equipararía con la de otros privilegiados, aquellos que tenían caballos valorados en 20 maravedíes, el alguacil y los dos alcaldes. Los trabajadores que no usaran «bobus vel bestiis» también tendrían que pagar pero en una menor cuantía.

La exención concedida a los vecinos de acudir en fonsado contra los musulmanes, ya fuera en servicio del prelado o del propio monarca, también supone un importante incentivo. Finalmente, otro aspecto a destacar es la remisión al fuero toledano en todo lo referente a las caloñas y homicidios.

la transcripción que realizó el padre Román de la Higuera. BNE, ms. 8196, ff. 86-87. Podemos encontrar el texto íntegro en: Merlos Romero, Yepes en la Edad Media..., p. 55.

44 IDEM. La autora data el fuero de Huerta en el año 1208, sin embargo, la transcripción efectuada por José Cepeda difiere en cuatro años. CePEDA AdÁn, "Repoblación...”, p. 20.

45 Algunos ya señalados por otros autores. Gorosterratzu Jaunarena, Don Rodrigo Jiménez..., p. 237.

46 BNE, ms. 8196, ff. 86-87.

47 Sirva como ejemplo Mojados, perteneciente al señorío de los obispos de Segovia. Bartolomé Herrero, "El señorío temporal...", p. 209. Junto a otras motivaciones dicha cuestión también provocó serios conflictos en Palencia. Nieto Soria, "La relación de poderes...", p. 636.

48 BNE, ms. 8196, ff. 86-87. 


\section{Proceso de consolidación del señorío arzobispal}

El cambio de titularidad experimentado en la propiedad de la antigua aldea ocasionó profundos cambios sociales y económicos. Muchas de las concesiones presentes en el fuero otorgado por el prelado tenían por objeto atraer a nuevos pobladores, hecho que sin duda debió de ocurrir en el transcurso de unos pocos años ${ }^{49}$. Los herederos de los vecinos de San Nicolás, en su mayoría avecindados en Toledo, no tardarían en mostrar su desagrado ante la pérdida del control sobre el lugar. Su protesta, vana, no tardó en producirse, logrando sin embargo determinar la actuación de los arzobispos de la sede primada en la zona.

En 1242, un año después de la elaboración de un posible controvertido acuerdo entre el prelado y el maestre de Santiago $0^{50}$, podemos constatar la existencia de dos bandos enfrentados en el seno de la villa. Al frente de los mismos se encontraban Martín de Elvira y Domingo Juan ${ }^{51}$. El cariz violento que adquirió la situación, contabilizándose dos muertes y varios heridos ${ }^{52}$, provocó la intervención del propio arzobispo, quien puso fin a la situación a través de la imposición de una serie de multas. Cualquier hombre o mujer que matara o hiriere a otra a causa de rencores pasados pagaría 10 maravedíes, precio que se incrementaría a 500 en el caso de producirse la reactivación de los bandos, bien a iniciativa de los propios vecinos o como consecuencia de la intervención de personas ajenas a la villa ${ }^{53}$. La cuantía sería repartida entre el prelado, el gobierno municipal y los enemigos de aquellos que incumplieran la concordia.

El origen del conflicto no queda reflejado en el documento de manera explícita, sin embargo dos de las disposiciones contenidas en él pueden ayudarnos a trazar alguna hipótesis al respecto. La primera se encuentra dirigida a los 5 jurados nombrados por el prelado con el objetivo de garantizar la paz: «que affinquen por los cotos que el conceio avrá puesto en aguas, e en exidos, e en carreras e en todas las otras cosas $\rangle^{54}$, incluyéndose más adelante la siguiente exhortación: «mandamos a vos el conceio que ayudedes a los jurados, e a los alcaldes e al alguazil pora recabdar los derechos de la

\footnotetext{
49 La procedencia de algunos de ellos puede ser deducida a través de sus motes o apellidos. En Melgar, aldea de Yepes, encontramos: al hijo del «gigant de Uerta» (¿de Valdecarábanos?), ACT V.7.A.1.5; a un hombre apellidado «de Salvanés» (topónimo presente en la actual Comunidad de Madrid), ACT V.7.C.1.11; otros dos apellidados Almazán y Navarro, y finalmente dos más conocidos como el Soriano y el «Morato». González Palencia, Los mozárabes..., doc. no 689. En la villa, ya en el siglo XIV, conocemos al hijo de Domingo de Ciruelos, ACT O.10.B.1.8; a Aly de Velilla, ACT I.5.C.1.15a; y a Bartolomé del Casar, ACT O.10.B.1.22. En Cabañas consta un gascón. ACT O.10.B.1.8.

50 Se establecieron una serie de villas faceras y se creó una comunidad de pastos y aprovechamiento de leña, quedando las dehesas al margen. GonzÁlez GonzÁlez, Repoblación de Castilla..., p. 337.

51 ACT O.10.B.3.4. Los bandos estarían encabezados presumiblemente por un mozárabe y un castellano.

52 IDEM. Los fallecidos fueron Martín Coriço y Portaguerra. Este último apellido coincide con el de uno de los pobladores castellanos de la cercana Dosbarrios en 1154. GonzÁlez GonzÁlez, Repoblación de Castilla..., p. 266. Los heridos parecen ser más numerosos, aportándose únicamente el nombre de Esteban y de Pascual, hijo de Domingo Juan.

53 Posible alusión a los vecinos de Toledo o a sus familiares.

54 ACT O.10.B.3.4.
} 
villa (...), e quien no les quisiesse ayudar pecharie doze maravedís, la meetat a nos e la meetat a los aportellados $\rangle^{55}$. La lectura de ambas nos lleva de nuevo a reiterar la posibilidad de que algunos de los descendientes de los parroquianos siguieran reivindicando su derecho a poseer una parte en la propiedad de las antiguas aldeas; negándose como consecuencia de ello a pagar impuestos ${ }^{56} \mathrm{o}$ a aceptar la regulación de la explotación de unos bienes comunales a compartir entre un número cada vez mayor de personas. Esta situación acabaría necesariamente enfrentándolos a los nuevos pobladores. La resolución del conflicto parece tener éxito aunque, por el momento, el arzobispo Rodrigo evite hacer acto de presencia en la villa, hecho deducible de la redacción del documento desde la cercana Ocaña ${ }^{57}$.

La convivencia y cohesión entre los vecinos debió de incentivarse a través de la ampliación del alfoz y el establecimiento de nuevos ejidos, proyecto no exento de dificultad. El emplazamiento de Yepes y la circunscripción de su primitivo término en una meseta en la que los recursos hídricos no eran abundantes, debió de constituir un serio problema para el proyectado desarrollo de la villa. Como se ha indicado con anterioridad la primera anexión en producirse fue la de la antigua villa de Fuentes ${ }^{58}$, a la que más tarde se añadiría Cabañas ${ }^{59}$. Ampliaciones de escaso valor, constituyendo los valles del arroyo Cedrón y del río Tajo los principales objetivos a alcanzar.

En el primero la sede primada ejercía desde su dotación la propiedad de Torres ${ }^{60}$, topónimo sustituido por el de Azebuch, «quae nunc dicitur Melgar», en la alusión que del citado privilegio lleva a cabo Jiménez de Rada en su Historia ${ }^{61}$. Seguramente el prelado hubiera concebido ya la idea de anexionar dicho enclave a Yepes, hecho que no tardaría en producirse ${ }^{62}$, pues en la concordia celebrada en 1213 con el concejo de La Guardia, en la que se concedía al lugar un extenso alfoz, es expuesto: «det nobis pro termino (...) rivum de Algodor, de Bogas usque Benquerencia, excepto eo quod pertinet

\footnotetext{
55 ACT O.10.B.3.4.

56 No todos los vecinos de San Nicolás propietarios en Yepes pertenecían a grandes linajes mozárabes, siendo ejemplo de ello Domingo el Hortelano o Micael el Esterero. GonzÁlez Palencia, Los mozárabes..., docs. $\mathrm{n}^{\mathrm{o}} 380 \mathrm{~b}$ y 1123 .

57 ACT O.10.B.3.4.

58 Producida cuando Yepes seguía en poder de la collación. En un contrato de compra-venta el camino de Fuentes es mencionado como próximo al término de Ciruelos, pudiendo el enclave encontrarse por lo tanto al noroeste de Yepes. ACT O.4.F.1.31. Véase el mapa aportado.

59 Hernández, Los Cartularios..., doc. $\mathrm{n}^{\mathrm{o}}$ 330. Aunque la primera mención que he podido encontrar de Cabañas como aldea inserta en el término de Yepes data del año 1339. ACT A.11.B.1.18. Cabeza y Pela constituirían en el período analizado meras explotaciones agrícolas en poder de las monjas de San Pedro de las Dueñas. Trillo Siaba, "Breve historia...", p. 9.

60 En las proximidades de Yepes existía un camino denominado de Torres. ACT 0, f. 46 v. Debido a ello no se puede asociar dicho enclave a Melgar y tampoco a la finca de La Torre, en Villasequilla, pues Mariano Maroto y Esperanza Martín parecen demostrar que dicho emplazamiento corresponde a la llamada Torre de Fernán Gudiel. Maroto Garrido y Martín Montes, Villasequilla..., pp.286-287.

61 Rivera Recio, "Patrimonio y señorío... ", p. 7.

62 La primera mención que he podido encontrar de Melgar como aldea perteneciente a Yepes data del año 1270. ACT V.7.C.1.11. Ello no permite asociar el proyecto de ampliación del alfoz de Yepes al arzobispo Rodrigo con total seguridad, siendo quizás obra de sus sucesores.
} 
ad Melgar $\rangle^{63}$. El enclave se encontraría en aquella época escasamente poblado, pues el cabildo decide donar al prelado en 1226, de manera vitalicia, la tercera parte del vestuario cobrado allí y en otras cuatro aldeas con el fin de contribuir a la llegada de nuevos habitantes ${ }^{64}$. En cuanto a la cercana población de Villaseca de Valdecarábanos no podemos constatar documentalmente su pertenencia a Yepes durante el período en el que se inscribe nuestro estudio. De la primera mitad del siglo XIII únicamente conservamos una serie de compras realizadas en el lugar a iniciativa de dos prelados y algunos eclesiásticos ${ }^{65}$. En 1213 el arzobispo Rodrigo compró por mediación de su mayordomo un octavo pro indiviso del lugar valorado en 68 mizcales. Quizás fuera la primera de una larga serie de compras desconocidas pues en la confirmación que de los bienes del arzobispo lleva a cabo Honorio III, en 1217, encontramos la inclusión de «Villam Siccam cum omnibus terminis suis» ${ }^{66}$.

La expansión hacia el norte, donde se encuentran ubicadas las fértiles vegas del río Tajo, presentó más dificultad y menos éxito. En el año 1252 se produjo un enfrentamiento entre el concejo de Yepes y Fernando, arcediano de Talavera y poseedor de Cinco Yugos por la Iglesia de Sigüenza. Los vecinos de ambas villas demandaban la anexión de unas tierras que hasta la fecha habían estado trabajando de manera conjunta. El arzobispo electo Sancho decidió no intervenir directamente en el pleito, ordenando al deán de Toledo y a los canónigos Agustín y Asensio la resolución del conflicto. Éstos se limitaron a reestablecer la situación existente en vida del arzobispo Rodrigo ${ }^{67}$, imponiendo multas a todo aquel que incumpliera lo acordado. El término de Yepes se ceñiría a la meseta sobre la que se emplaza la población y el de Cinco Yugos al valle del Tajo. Las tierras sin labrar y las laderas entre ambas serían explotadas de manera conjunta (caza, aguas, pastos, leña y esparto) ${ }^{68}$. Para los vasallos del prelado, quienes sin duda estarían intentando descender la meseta y ocupar la ribera, no debió de constituir una grata resolución.

La villa arzobispal y sus aldeas se encontraban en gran parte rodeadas por territorios pertenecientes a las órdenes militares de Santiago y Calatrava ${ }^{69}$. Ello trajo consigo la

\footnotetext{
63 Fita Colomé, "La Guardia...”, p. 379; Hernández, Los Cartularios..., doc. no 340.

64 Fita Colomé, "La Guardia...”, p. 384; Hernández, Los Cartularios..., doc. no 417.

65 González Palencia, Los mozárabes..., docs. no 393, 536, 552, 575, 576, 599 y 600; Maroto Garrido y Martín Montes, Villasequilla..., pp. 70-73.

66 No parece que se trate de Villaseca de la Sagra. ACT I.12.A.1.5; Fita Colomé, "La Guardia...”, p. 382; Mansilla, La documentación..., doc. nº 31.

${ }_{67}$ El prelado elaboró varias concordias con el fin de regular el uso de los recursos naturales cercanos a algunas villas episcopales. En 1221, actuando como administrador del obispado de Segovia, llegó a un acuerdo con una serie de pueblos próximos a Collado Hermoso en relación con el uso de las aguas del río Pirón. Bartolomé Herrero, “El señorío temporal...”, p. 204.

68 ACT I.3.M.1.1. Afectado por polilla. En el Archivo Municipal de Yepes se ha conservado un traslado del mismo elaborado en 1348 a raíz del problema indicado. Se realizó a iniciativa de los alcaldes de la villa arzobispal, Domingo y Roy Pérez, tras ser revisado por Juan Aparicio y Domingo Juan, respectivamente juez y notario de la corte del arzobispo Gil de Albornoz. AMY, perg. no 4.

69 Vid. Lomax, “El arzobispo...”, pp. 323-365; Hernández, Los Cartularios..., doc. no 385.
} 
necesaria elaboración de una serie de acuerdos entre los maestres y los titulares de la sede primada, ambos dispuestos a establecer entre sus poblaciones unas fronteras definidas ${ }^{70}$. En torno al año 1270 los vecinos de Yepes y los de la cercana Ciruelos comenzaron a reclamar la propiedad del valle Retamoso, situado en la frontera que separaba los términos de ambos lugares. En el mismo se explotaban pastos, caza, y leña (atochas, retamas y carrascas). ${ }^{71}$ El arzobispo Sancho de Aragón, con anuencia del deán Sancho Martínez y de los canónigos presentes, acordó con el maestre de Calatrava, Juan González, lo siguiente:

«que de la carrera toledana que disen fasta los montes que son contra Yepes e contra Çiruelos que se partan en tres partes este término sobre que era la discordia, e las dos partes que serán contra Yepes e contra Ciruelos que los de Yepes e los de Çiruelos usen en esta manera, es a saber, que corten e pascan e caçen (...), también los de parte de la Orden como los de parte del arçobispo, e que non labren por pan más de quanto está en día labrado. Propiedat destas

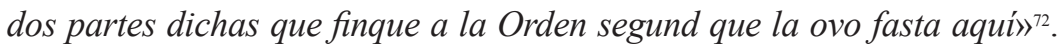

En el amojonamiento de los términos cabe destacar la asistencia ${ }^{73}$ de Fernando Mateos, alcalde del rey, pues hasta entonces, como hemos tenido ocasión de comprobar, la intervención de la monarquía en la resolución de los conflictos que afectaron a la villa fue inexistente.

El problema resurgió en 1371, teniendo los procuradores de Yepes ${ }^{74}$, junto con los de Ciruelos, que comparecer a juicio ante el capiscol Juan Alfonso y el bachiller en decretos $^{75}$ Diego Ferrándes. La sentencia pronunciada no debió de agradarles, siendo presentada como consecuencia de ello una apelación ante el arzobispo. En ella se alegó la existencia de pruebas que no habían tenido ocasión de presentar en la vista, la composición de 1270. Gómez Manrique accedió a la petición de sus vasallos e instó al capiscol a hacer cumplir la sentencia dada por su predecesor, tomando las medidas necesarias para acabar con los enfrentamientos ${ }^{76}$.

\footnotetext{
70 A modo de ejemplo, con los caballeros de Santiago se llevan a cabo en 1215 y en 1219. En dichos años quedan definidas las fronteras entre las tierras de la Orden y las del arzobispo. Merlos Romero, Yepes en la Edad Media..., pp. 45 y 55.

71 AMY, perg. $n^{\circ} 9$.

72 IDEM.

73 IDEM. A él acudieron Pedro Martínez de Salamanca, maestrescuela de Palencia y canónigo de Toledo, el caballero toledano Diego Alfón y el comendador de Otos.

74 AMY, perg. $\mathrm{n}^{\circ}$ 9. El concejo de la villa arzobispal, tras reunirse a campana repicada, designó como sus procuradores a Gonzalo Martínez y Alfonso Sánchez. Hijos de Domingo Juan y de Domingo Pérez respectivamente.

75 También ejercía el cargo de tesorero de la sede primada.

76 AMY, perg. $n^{\circ}$ 9. Los jueces acataron la decisión, limitándose a establecer una pena de 20.000 maravedíes al concejo que incumpliese la sentencia, ordenando asimismo la devolución de las prendas efectuadas en los dos últimos años.
} 
No conocemos el papel que debió de ocupar en estas disputas el llamado Ochavo de Ciruelos, comprado a María Pérez por el arzobispo Rodrigo en 1232 y entregado años más tarde por su sucesor Sancho de Castilla a Domingo Pérez. El valor de la propiedad para la mesa arzobispal debía de ser considerable pues su recuperación supuso la pérdida de los bienes y vasallos que el prelado poseía en Peñafiel ${ }^{77}$.

Las sentencias pronunciadas por los jueces eclesiásticos no siempre eran tenidas en cuenta, resurgiendo en más de una ocasión los conflictos a los que habían intentado poner fin. Dicha situación fue común en la Edad Media, mostrándose reticentes a abandonar sus reivindicaciones algunos concejos y vecinos. Los vasallos de la Iglesia sufrieron reiteradamente el problema teniendo que ver, por ejemplo, cómo les eran arrebatados unos recursos naturales cuya explotación les pertenecía ${ }^{78}$.

La consolidación del señorío no sólo se logró por medio de la expansión territorial, el aumento de propiedades en manos de eclesiásticos también pudo contribuir a ello. Sirva de ejemplo ${ }^{79}$ Gonzalo, clérigo de Yepes, quien compró entre los años 1269 y 1277 una larga serie de bienes de tipo diverso, algunos de ellos junto a su hermana ${ }^{80}$. En 1286 vendería un total de 36 fincas, bienes y ganado al vicario García Estebann ${ }^{81}$, comprador este último de 5 tierras, 1 corral y 3 chozas en $1289^{82}$. El arzobispo Rodrigo también llevó a cabo una importante labor adquiriendo algunas de las propiedades en poder de personas avecindadas en Toledo ${ }^{83}$.

En último lugar cabe preguntarse el papel que pudieron haber ejercido las defensas de la villa y su alfoz en el proceso de consolidación del señorío, es decir, si es en este momento o no cuando se inicia la refortificación del territorio con fines coercitivos. En relación a ello y con motivo de haberse reservado en este artículo un apartado exclusivo al respecto, únicamente señalaremos que en la segunda mitad del siglo XIII parece tener lugar la construcción del primer recinto amurallado de Yepes, del castillo de Melgar y de la torre de Cabañas.

\footnotetext{
77 Rodríguez-Picavea, “Documentos para el estudio...”, docs. nº 665 y 678.

78 Los vecinos de Riaza, ubicada en la diócesis de Segovia, tuvieron que solicitar reiteradamente ayuda a su señor el obispo con el fin de alejar de sus tierras a los concejos de Sepúlveda y Fresno. BARTOLOMÉ Herrero, "El señorío temporal... ", pp. 204-205.

79 Podríamos mencionar también a París, presbítero de Santiago del Arrabal, quien en 1214 permuta a Juan Pétrez una viña en Azucaica a cambio de una propiedad en Yepes. GonzÁlez Palencia, Los mozárabes..., doc. $\mathrm{n}^{\mathrm{o}} 420$

80 ACT V.7.C.1.12; ACT V.7.A.1.5; ACT V.7.C.1.11; ACT Z.11.B.3.7.

81 González Palencia, Los mozárabes..., doc. nº 689.

82 IBÍDEM.

83 En 1215 compra una heredad a la viuda de Melendo, alguacil y alcalde de Toledo. GonZÁlez PALENCIA, Los mozárabes..., doc. no 420 .
} 


\section{Conflictos jurisdiccionales con el concejo de Toledo}

Desde el reinado de Sancho IV se puede observar un incremento de las tensiones entre la Iglesia y los vecinos de Toledo. El origen y consecuencias de las mismas así como el modo de afrontarlas carecieron de homogeneidad, pudiéndose constatar al respecto ciertas variaciones con el paso de los años. A través del señorío arzobispal que nos ocupa intentaremos realizar una aproximación a dicho proceso ${ }^{84}$.

La segregación de Yepes del alfoz toledano no parece constituir en el siglo XIII un objeto serio de debate, al margen quizás de la lucha de bandos acontecida en $1242^{85}$. En favor de ello contamos con un documento de 1301 en el que el rey Fernando IV, a petición de los vecinos de la ciudad, prohíbe la entrada de vino en Toledo procedente de Yepes «et de los otros lugares que non sson de ssu término»».

De igual modo la villa arzobispal parece eludir los conflictos surgidos en 1295 a raíz de la prematura muerte del rey Sancho IV. No en vano, su nombre no acompaña al de Acalá, Brihuega, Uceda y Talamanca en los documentos relativos a la Hermandad de los Concejos de la Extremadura castellana y del Arzobispado de Toledo ${ }^{87}$. Quizás dicho aspecto fuera el que motivara al prelado Gonzalo Díaz Palomeque, en 1304, a confirmar los privilegios y exenciones de las que gozaba el enclave ${ }^{88}$. Del documento destaca la siguiente exhortación: «mandamos al que tiene los dichos logares de nos en préstamo, e los toviere cabe adelante, o a los que los tovieren por nos o por ellos (...) que les non passen contra estas cosas que les nos conffirmamos $\rangle^{89}$. Afirmación que nos podría indicar que, en aquellas fechas, la villa objeto de nuestro estudio se encontraba en poder de un beneficiario hoy desconocido ${ }^{90}$.

\footnotetext{
84 Analizado por Hilda Grassotti en relación a Illescas. Vid. Grassotti, Estudios..., pp. 155-169.

85 Entre las reivindicaciones hechas a la sede primada por parte del concejo de Toledo, en el siglo XIII, no encontramos ninguna alusión directa a Yepes, no obstante, la villa y sus vecinos pudieron sufrir desde finales del reinado de Sancho IV las consecuencias de las numerosas intromisiones cometidas en la jurisdicción eclesiástica. Vid. Nieto SoRIA, José Manuel, Las relaciones monarquía-episcopado..., pp. 191-195.

86 AMT, cajón 3. Leg. 4 n 1 1. Izquierdo Benito, Privilegios Reales..., doc. $\mathrm{n}^{\circ} 44$.

87 En relación con ella consúltese: Asenjo GonzÁlez, "Ciudades y hermandades... ", pp. 103-146; García De Valdeavellano, "Carta de Hermandad...", pp. 69-76; Nieto Soria, Iglesia..., p. 193.

88 AMY, perg. $\mathrm{n}^{\circ}$ 2. El prelado afirma otorgar la merced como muestra de gratitud ante los grandes y señalados servicios que le habían prestado a él y a la Iglesia. Idéntica motivación consta en la confirmación de los privilegios de La Guardia. Fita Colomé, "La Guardia...", p. 415. Ambas villas pudieron negarse a actuar al margen de su señor e integrar la citada Hermandad, siendo ahora recompensadas.

89 AMY, perg. $n^{\circ} 2$.

90 No podemos vincular la confirmación de los privilegios al origen de la cesión o al surgimiento de problemas en torno a ella. Ese mismo año se otorga la misma merced a la villa de La Guardia. El contenido de ambos documentos es prácticamente idéntico salvo en la cuestión relativa al préstamo: «é mandamos al alcayde, é al nuestro mayordomo, é á todos otros nuestros homes, que estovieren en la guardia por nos, (...) que les non faran contra questas cosas, que les nos confirmamos». Fita Colomé, "La Guardia...", p. 415.
} 
El mismo arzobispo intentaría con posterioridad reducir las cargas y agravios sufridos por sus vasallos a causa de las exigencias tributarias de la corona ${ }^{91}$. En 1313 instó a los vecinos de Yepes $^{92}$, La Guardia y Almonacid a afrontar el pago del yantar de manera conjunta, evitando de este modo que la cuantía recayera íntegramente sobre la población en que tuviera lugar la visita regia ${ }^{93}$. Dicho impuesto ya había suscitado problemas once años antes ${ }^{94}$ ante la pretensión por parte de los recaudadores de cobrarlo en moneda ${ }^{95}$.

Iniciado el reinado de Alfonso $\mathrm{XI}^{96}$ observamos cómo el concejo toledano parece haber cambiado radicalmente de posición, abandonando su política proteccionista en favor de la reivindicación directa de la jurisdicción sobre Yepes y otros enclaves pertenecientes a la Iglesia. En la villa arzobispal existía una gran cantidad de propiedades en poder de personas avecindadas en Toledo «de muy grand tiempo acá, dello por herençia e dello por compras $^{97} \gg$. No obstante, éstos consideraban estar al margen del señorío eclesiástico, negándose por ende a prestar servicios o a pagar impuestos ${ }^{98}$. Dicho "privilegio" lo hacían extensible a las personas que trabajaban, arrendaban o compraban sus casas y solares $^{99}$. No es de extrañar por tanto que algunos vasallos de la Iglesia abandonaran sus posesiones y adquirieran aquellas ofertadas por los toledanos en perjuicio del abadengo. El problema fue abordado de distinta manera por los sucesivos prelados que ocuparon la sede primada, al menos en lo que respecta a la villa objeto de nuestro estudio. Juan de Aragón pudo llevar a cabo la construcción de un alcázar adosado a la entrada principal de la población, del que restaría la denominada torre sur del primer recinto amurallado $^{100}$. Siguiendo una política radicalmente opuesta, Jimeno de Luna optó por la

\footnotetext{
91 No parece existir por tanto una relación conflictiva entre el prelado y sus vasallos, situación que sí se produciría en otros lugares. Sirva de ejemplo la actitud mostrada por el obispo conquense García para con sus vasallos de Pareja y Casasana a mediados del siglo XIV. Díaz IbéÑ̃zz, Iglesia, sociedad ..., pp. 98-99. 92 Tales visitas debieron de ser frecuentes en Yepes, allí consta la existencia en 1357 de una casa dicha del rey y de una calle homónima. ACT O.10.B.1.17; ACT O.10.B.1.12.

93 Destaca del citado documento el sello del concejo de Yepes, descrito por el padre Fita, en el que se podía observar una cruz de Calatrava acompañada de cuatro cruces más. Fita Colomé, "La Guardia...", p. 416 .

${ }_{94}$ AMY, perg. $\mathrm{N}^{\circ}$ 11. El privilegio se encuentra inserto en una confirmación del mismo efectuada por el rey Juan I a instancias del arzobispo Pedro Tenorio en 1385.

95 Dicha documentación se encuentra analizada junto a casos similares, ocurridos tanto en Toledo como en otras zonas de Castilla, en: NiETo SORIA, José Manuel, Las relaciones monarquía-episcopado..., pp. $348-352$ y 442.

96 El paso de tierras de realengo a abadengo, y viceversa, constituyó un objeto frecuente de debate en las cortes castellanas desde finales del siglo XIII. Acerca ello: NieTo Soria, Iglesia y poder..., pp. 136-146.

97 ACT Z.5.C.1.10.

98 IDEM.

99 Ello es expuesto en Esquivias donde los toledanos daban sus casas y solares a personas a las que eximían de impuestos, considerándoles sus solariegos. ACT O.1.E.1.2.

${ }^{100}$ En relación a Illescas se tiene constancia de la decisión por parte del prelado de construir un alcázar adosado a la denominada Puerta del Sol. Grassotti, Estudios..., pp. 155-169. Por ello nos atrevemos a vincular la construcción de la denominada torre sur de Yepes a este período de inestabilidad coincidente con la minoría de edad de Alfonso XI. En 1352 el arzobispo Gonzalo de Aguilar emite ya documentación desde la villa, lo que nos podría indicar la existencia de un palacio o alcázar que sirviera de residencia a los titulares de la sede primada. ACT X.10.A.2.6.c.
} 
mediación regia logrando que, en 1332, Alfonso XI ordenara a los vecinos y concejo de Toledo no embargar la jurisdicción del prelado sobre Yepes y sus aldeas ${ }^{101}$. La lectura del documento, no obstante, nos indica que se trata de una sentencia provisional pues emplaza a las partes implicadas a personarse en la corte en caso de disconformidad.

Por su parte, Gil de Albornoz afrontó el problema a través de la elaboración de concordias. Ejemplo de ello es la llevada a cabo con el concejo toledano en $1346^{102}$. A través de la misma se estableció el pago de ciertos impuestos a los vecinos de la ciudad que poseyeran propiedades en tierras de la Iglesia ${ }^{103}$ (en muro, puente y fuente); eximiéndoles en cambio de contribuir en acémilas, yantares, servicios, pechos u otros derechos aforados. Asimismo se estableció que entregaran en la casa de palacio de lo que no es tributado la décima parte de las uvas que recolectaran en Yepes y otros enclaves. En el caso de que su producción fuera cerealista, anualmente deberían de entregar por cada yugada seis fanegas de pan, mitad en trigo y mitad en cebada. En el caso de que optaran por abandonar la explotación durante más de cinco años, ésta podría ser vendida de manera forzosa a un precio previamente establecido en función de su extensión.

Otra serie de disposiciones establecidas a instancias de la Iglesia se centran en impedir la pérdida de sus vasallos. Los toledanos no podrían vender a éstos ningún tipo de propiedad ${ }^{104} \mathrm{y}$ tampoco podrían tenerlos como apaniaguados. En cuanto aquellos que ya se encontraran en dicha situación, tendrían que pagar los impuestos correspondientes.

Los términos presentes en el documento no parecen tener gran recorrido, pudiendo ser cumplidos quizás hasta el estallido de la guerra civil ${ }^{105}$.

La necesidad por parte de Enrique II de ganar el mayor número de adhesiones posibles a su causa, agravó de por sí una situación compleja. En el mes de septiembre del año 1366 el hermanastro del rey, bajo petición del arzobispo Gómez Manrique, aprovecha su breve estancia en Toledo para dirigir una carta al concejo de la ciudad. En ella se informaba de la confirmación de un privilegio dado por el rey Sancho IV en el que instaba a los vecinos de la ciudad a respetar la jurisdicción eclesiástica ${ }^{106}$. Dos años más tarde el pretendiente al trono reincidiría en la cuestión estableciendo desde Illescas que:

«por rasón quel arçobispo de Toledo e la su eglesia an cartas de pr[e]villejios de los reys en que se contiene quel dicho arçobispo e la dicha su eglesia ayan la justiçia çevil e cr[i]minal de todas las villas e logares del dicho arçobispo, e otrosí de la dicha su eglesia, nos (...) mandamos que los alcalldes e (...)

\footnotetext{
101 ACT 0.10.B.1.2. Merlos Romero, Yepes en la Edad Media..., p. 57.

102 Con el propósito de que los toledanos que tuvieran posesiones en tierras de la Iglesia pecharan en ellas. ACT Z.5.C.1.10. Ocho años antes había confirmado otra concordia elaborada en 1294. ACT Z.5.C.1.8.b.

${ }_{103}$ Aunque hay que señalar que Yepes ocupa un espacio destacado en el documento.

${ }^{104}$ En cambio, sí podrían vender sus propiedades a otros vecinos de la ciudad tras explicarles los términos de la concordia. ACT Z.5.C.1.10.

${ }^{105}$ El rey Enrique II se vio obligado en 1361 y 1375 a confirmar la concordia, lo que nos puede indicar su reiterado incumplimiento. ACT Z.5.C.1.10a; ACT Z.5.C.1.10.

106 AMY, perg. $n^{\circ} 7$.
} 
ofiçiales (...) oyan e conoscan por qual manera quier que sea e fagan justiçia de todos los pleytos [çeviles, criminales] ${ }^{107}$ que (...) acaesçieren de aquí adelante en qualquier manera en el dicho logar de Yepes e en su término» ${ }^{108}$.

Acabada la guerra, con el propósito de congraciarse con el antiguo bastión petrista, el nuevo rey confirma en 1369 los privilegios y libertades de Toledo. Ello afectaría seriamente a la sede primada pues en el documento fue incluido: «vos tornamos toda la justiçia çevil et criminal et juridisçion que vos avedes et aver devedes en todos los logares que la oviste en el tienpo de los dichos rreyes $\left.{ }^{109}\right\rangle$. Dicha afirmación permitiría la reivindicación de algunas de las aldeas que en su día pertenecieron al antiguo alfoz de la ciudad.

En Yepes, el arzobispo Manrique acabó con la permisividad mostrada por sus predecesores frente a los vecinos de Toledo propietarios en el lugar, invalidando seguramente la concordia aprobada en 1346. La confirmación de la misma por parte de Enrique II en $1375^{110}$ parece constituir una prueba de ello.

La situación derivada de la muerte del citado prelado ${ }^{111}$ fue aprovechada por el rey, quien no dudó en otorgar la jurisdicción de la villa a los toledanos ${ }^{112}$. Éstos alegaban haber estado en posesión de la misma desde el reinado de Alfonso XI hasta su usurpación por parte de Gómez Manrique. De ser verdad, seguramente habrían juzgado únicamente los pleitos relativos a sus apaniaguados. Juan Gómez, alcalde de Yepes, continuaba juzgando en 1359 los casos concernientes a los vasallos del arzobispo ${ }^{113}$. Por tanto, el concejo de Toledo mentía al afirmar que había estado en posesión de la justicia civil y criminal del lugar.

En el mes de junio del año 1376 una comitiva toledana ${ }^{114}$ se dirigió a Yepes con el objetivo de hacer cumplir la sentencia regia. El gobierno municipal de la villa ${ }^{115}$, congregado en

\footnotetext{
107 AMY, perg. $\mathrm{n}^{\mathrm{o}}$ 8. El documento se encuentra en gran parte borrado, pero se intuye perfectamente çeviles y el inicio de la siguiente palabra en $\mathrm{cr}$. El regesto de 1840 indica que el rey entrega la jurisdicción a los alcaldes de Yepes.

108 IDEM.

109 Se refiere a todos los monarcas que le precedieron, pero en especial a su padre. IzQUIERDo Benito, Privilegios Reales..., doc. $\mathrm{n}^{\circ} 89$.

110 ACT Z.5.C.1.10.

111 El prelado se habría mostrado reacio a ceder ante las pretensiones de los toledanos, no contentándose con las numerosas mercedes obtenidas del monarca. Algunas tan generosas como la donación de Talavera. Sobre el prelado y su relación con la corona respecto a Illescas consúltese: GRAssotTI, "Otra vez...", pp. 39-70.

112 Molénat, Campagnes et monts..., p. 390 y 537; Merlos Romero, Yepes en la Edad Media..., p. 57.

113 En 1359 la viuda María es demandada ante Juan Gómez, alcalde de Yepes, por el judío de Ocaña Abrahem Abzaradiel, recaudador del pan por el rey Pedro en el arciprestazgo de La Guardia, a quien debía 944 maravedíes. La vecina de Melgar perdería con el pleito casas, tierras y viñas. AMY, perg. $n^{\circ}$ 6; LeÓn Tello, Judios..., doc. no 529.

114 Se encontraba integrada por Ruy Pérez, alcalde de la justicia por el alcalde mayor Pedro Suárez, y el alguacil mayor Juan Garcilaso, en el cargo por Juan Fernández de Padilla. AMT, caj. 7, leg. 2, no 4.

115 Encabezado por los alcaldes Pedro Martínez y García Pérez.
} 
el portal de la iglesia de San Benito ${ }^{116}$, decidió momentáneamente aceptar la imposición. No obstante, pidió demorar la resolución de la cuestión hasta el nombramiento de un nuevo arzobispo pues suya «era la dicha villa (...) e la jurediçión»» ${ }^{117}$. La respuesta debió de desagradar a los toledanos. Ruy Pérez y Juan García acudieron a la casa del alguacil de la población para manifestarle que, en adelante, todas las detenciones las haría en nombre de la ciudad de Toledo. La orden fue materializada en la confiscación y posterior entrega de la cadena a la que eran sujetos los reos. El derribo de los dos pilares que conformaban la horca con picos y azadones no tendría lugar hasta el anochecer ${ }^{118}$. La relación de los hechos efectuada por la Iglesia difiere de la presentada por el concejo de Toledo en algunos aspectos, recalcando el carácter militar de la visita:

«los dichos ofiçiales, e cavalleros, e escuderos e común de Toledo (...), por su propia autoridat e osadía desordenada, (...) fueron a la dicha villa de Yepes armados, e con yra e sobervia (...) derribaron la forca que y çerca (...) estava puesta por los ofiçiales de la dicha eglesia, e esforçosamente que entrasen en la carçel de la dicha villa e sacaran dende los omes que y tenien presos. (...) Disiendo que Toledo avía derecho (...) de la dicha jurediçión çevil e creminal (...) prendien los vesinos de la dicha villa e traýenlos presos a Toledo (...) apremiándoles por fuerça venir a juysio» ${ }^{119}$.

El posterior nombramiento de Pedro Tenorio dio inicio al proceso de recuperación de la jurisdicción. En el Archivo Capitular se ha conservado un extenso documento en el que el prelado da respuesta a todos y cada uno de los alegatos presentados por los toledanos ${ }^{120}$. Ya en la primera página queda reflejado: «la villa de Yepes es de la eglesia de Toledo e tiene $p$ [riville]gios que aya en ella la juridiçión çevil e criminal, e el mero $e$ [mixto] imperio, e siempre fueron senores della e usaron de la dicha juridiçión los arçobispos (...), espeçialmente don Gomes $\left.{ }^{121}\right\rangle$.

Finalmente, el 16 de febrero del año 1384, Juan I parece ${ }^{122}$ dar la razón a Pedro Tenorio, instando a los toledanos a devolver al arzobispo la jurisdicción sobre Yepes, pagar las costas establecidas en el juicio y levantar la horca en el lugar en el que estaba ${ }^{123}$.

El arzobispo alegaría ante los oidores del rey:

\footnotetext{
116 AMT, caj. 7, leg. 2, no 4.

117 IDEM. Suceso mencionado por Molénat. MolÉnAt, Campagnes et monts..., p. 390 y 537.

118 IDEM

119 AMY, perg. n' 10 .

120 ACT A.8.H.1.11.

121 IDEM.

122 Recordemos el incumplimiento de la sentencia promulgada por el rey Alfonso XI, fruto seguramente de la presentación de un recurso por parte de los procuradores del concejo de Toledo.

123 AMY, perg. n' 10 .
} 
«la dicha eglesia de Toledo (...) e los otros arçobispos que fueron della (...) poseyeron (...) por tanto tiempo que non era memoria de omes en contrario las villas de Alcalá de Henares, e de Briuega, e de Useda, e de Talamanca, e de Yepes, e de La Guardia, e de Caçorrlla e de Esnatoraf (...) con todas sus aldeas e términos (...) e con toda su jurediçión temporal, así çevil como creminal, usando della por sí e por sus alcaldes e ofiçiales, que ponían e ponien los dichos arçobispos de cada ano en cada una de las dichas villas, (...) e tenien en cada una de las dichas villas carçel con cadenas (...) en que tenían e tienen presos e guardados los malfechores, e forca» ${ }^{124}$.

La resolución no conllevaría el fin de las intromisiones por parte de los toledanos. En el mes de diciembre del año 1387 se cometió un robo a las puertas de la iglesia de Melgar, tres ladrones habían perseguido a dos viajeros catalanes hasta la aldea con el fin de hacerse con su dinero ${ }^{125}$. Los afectados presentaron una querella ante los alcaldes de Yepes, quienes iniciaron una exitosa investigación encontrando apresado en Toledo a uno de los implicados, Pedro Fernández Mesonero. Juan González, alcalde en la ciudad por Pedro López de Ayala, se negó a entregar al preso, alegando que sus predecesores se habían encargado de dirimir todos los pleitos civiles y criminales acontecidos en el enclave. Algo radicalmente opuesto a lo afirmado por los procuradores de la villa arzobispal:

«Melgar, que era a una legua de Yepes, era su aldea e era en su término (...), e así fuera avida e reputada (...) de tanto tiempo acá que memoria de omes non era en contra, et oviera siempre la villa de Yepes la jurisdiçió çevil et criminal en la dicha aldea e su término así como en las otras sus aldeas del su término ${ }^{126 \%}$.

Como consecuencia de ello se inició una nueva querella que se dilataría hasta el mes de marzo del año $1389^{127}$, fecha en la que el monarca emitió su resolución. Juan González se vio obligado a entregar al preso a los alcaldes y alguacil de Yepes para ser juzgado ${ }^{128}$. Algunas de las respuestas presentadas ante los problemas surgidos en el siglo XIV son idénticas a las esgrimidas en el siglo anterior. De este modo se puede constatar en

\footnotetext{
124 AMY, perg. $\mathrm{n}^{\circ} 10$.

125 AMY, perg. $n^{\circ} 12$.

126 IDEM.

127 Un año más tarde se producirá un grave enfrentamiento entre el cabildo de Toledo y el concejo de dicha ciudad, dispuesta a reivindicar la jurisdicción criminal sobre Torrijos. La corporación municipal toledana será humillada en una ceremonia pública celebrada en las inmediaciones de la catedral. IzQUIERDO BEnIto, “Conflictos...", pp. 1.081-1.103.

128 AMY, perg. n' 12 .
} 
la villa la compra de propiedades en poder de personas avecindadas en Toledo ${ }^{129}$ y la realización de obras de fortificación, de las cuales hablaremos en el siguiente apartado. En relación al "proceso de expulsión" de los toledanos ${ }^{130}$, se han podido constatar cinco compras $^{131}$. En cambio, únicamente se ha conservado el testimonio de una permuta. En 1393 Fernando Alfón, antiguo alcalde de Toledo, obtiene una tierra en el término de dicha ciudad a cambio de la entrega de una viña situada en Yepes ${ }^{132}$.

De menor utilidad resultaría para el prelado la elevada presencia de clérigos en la villa y su alfoz. Los contratos de compraventa al respecto son muy elevados ${ }^{133}$. El cabildo por su parte también contó con una larga serie de propiedades, obtenidas en su mayoría a través de donaciones ${ }^{134}$.

Todas estas empresas, sin embargo, resultarían vanas. La presencia toledana en tierras de abadengo seguiría suponiendo una seria y constante amenaza. A comienzos del siglo siguiente se afirma de Cabañas: «todo el logar está en poder de cavalleros, escuderos e clérigos de Toledo, e de vuestros vasallos puede aver fasta quarenta e çinco, e de los de Toledo muchos, en manera que ellos se son señores del logar por comprar (...) las heredades $\rangle^{135}$. Situación similar a la experimentada en Yepes donde se afirma que la presencia toledana en la villa tiene como finalidad «meter en Toledo sus vinos e esquilmos»»

\section{Fortificación del señorío}

Ante el propósito de analizar el papel ejercido por las fortificaciones en la consolidación, desarrollo y defensa del señorío, resulta imprescindible en primer lugar determinar el posible origen de las mismas.

\footnotetext{
129 También a aquellas avecindadas en poblaciones pertenecientes a la Orden de Calatrava. En 1359 Alvar López, racionero de la Iglesia de Toledo, compra una viña en término de Yepes a Urraca y a sus hijas, moradoras en Ciruelos. Por su parte, Pedro Sánchez, clérigo de San Nicolás de Toledo, compra en 1338 una viña a Domingo Pérez, morador en una aldea de Huerta. ACT O.10.B.1.11; ACT V.12.Z.1.17.

${ }^{130}$ La compra frecuente de propiedades en Yepes por parte de clérigos a los vasallos de la mitra puede llegar a poner en duda la existencia de una política prediseñada con el fin de llevar a cabo dicho proceso. 131 El clérigo Pedro Sánchez adquiere en 1339 y en 1346 dos viñas, una situada en Cabañas y otra en las Rozas de Yepes. Más tarde, Fernando Martínez, despensero del cardenal Gil de Albornoz, logra comprar una heredad y una viña en Yepes. El racionero Alvar López, por su parte, compra en 1363 una viña al pergaminero Rodrigo Alfonso. ACT A.11.B.1.18; ACT O.10.B.1.21; AMY, perg. $\mathrm{n}^{\circ}$ 5; AMY, perg. $\mathrm{n}^{\circ}$ 3; ACT 0.10.B.1.22.

132 ACT O.10.B.1.9.

133 El racionero de la Iglesia de Toledo, Alvar López, lleva a cabo en 1357 la compra de la mitad de un lagar y dos viñas. El arcediano de Talavera, Alfonso Fernández; el clérigo de San Nicolás, Pedro Sánchez o el racionero de la Iglesia de Toledo y arcipreste de Alcalá, Juan Fernández de Mora, también se incluyen entre los nuevos propietarios. ACT O.10.B.1.17; ACT O.10.B.1.10; ACT O.10.B.1.11; ACT O.10.B.1.5; ACT V.12.Z.1.17; ACT O.4.F.1.31; ACT I.5.C.1.15a; ACT O.10.B.1.14; ACT O.10.B.1.16.

${ }_{134}$ GonzÁlvez Ruiz, Hombres y libros..., p. 629. Para la segunda mitad del siglo XIV consúltese: IzQuierdo Benito, El patrimonio del cabildo..., pp. 108, 113 y 119.

135 Benito Ruano, "Visita de las villas...", p. 86.

136 IDEM.
} 
En el documento elaborado con motivo de la partición de los términos entre la aún aldea y Ocaña, datado en 1215, se indica que Yepes fue donada al «concejo» de San Nicolás «con su castiello e con su xara» ${ }^{137}$. El hecho de que la jara se ubicase próxima al límite entre los términos de ambas poblaciones (El Aljibe), nos puede indicar que el castillejo también pudiera encontrarse cerca, siendo por tanto objeto de litigio y nombrado en el deslinde. Ello nos lleva a plantearnos serias dudas respecto a la existencia de la citada edificación dentro del casco urbano.

En relación al primer recinto amurallado de la villa, se ha señalado su posible origen musulmán con motivo del hallazgo de una serie de paralelismos existentes entre algunas de las partes conservadas y varias construcciones islámicas ${ }^{138}$. En mi opinión dicho planteamiento podría ser erróneo. En las denominadas torres central y sur se ha vinculado el empleo de mampostería con verdugadas de ladrillo a una primera fase constructiva anterior al año $1145^{139}$. Su uso, sin embargo, es constatable en otras obras emprendidas por la mitra en fechas mucho más tardías ${ }^{140}$. Otro aspecto a tener en cuenta, en ambas torres, es el uso de dicha técnica únicamente en la sección destinada a alojar las escaleras. Por ello me inclino a asociar dicha técnica constructiva a un proyecto de rehabilitación de la fortificación llevado a cabo en el siglo XIV, aspecto sobre el que reincidiremos más adelante.

La cerca primitiva debió de estar constituida por un muro de mampostería dotado de torres, del mismo material, con planta en forma de U. Ello se deduce de la observación de la torre central, muy reformada con posterioridad, y de la desgraciadamente ya inexistente ubicada en el costado este de la calle Luna ${ }^{141}$. La ausencia de documentación relativa al recinto nos impide conocer el momento aproximado en el que pudo ser levantado. No obstante, no parece razonable atribuir su construcción a Rodrigo Jiménez de Rada teniendo en cuenta las tensas relaciones existentes entre el prelado y una buena parte de sus vasallos ${ }^{142}$. Por tanto, cabe plantearse la posibilidad de que las obras de construcción pudieran haber tenido su origen en la segunda mitad del siglo XIII, una vez lograda la pacificación de la población y como medio disuasorio ante un posible rebrote de hostilidad. Dicho período coincide con la fortificación de otros enclaves de

\footnotetext{
137 Hernández, Los Cartularios..., doc. no 360; Merlos Romero, Yepes en la Edad Media..., p. 45.

138 Sobre el análisis estilístico de las torres de Yepes y las distintas propuestas de datación al respecto consúltese: Merlos Romero, Yepes en la Edad Media..., pp. 99-146.

139 Merlos Romero, Yepes en la Edad Media..., p. 141.

${ }^{140}$ Un ejemplo de ello es el cuerpo añadido a la torre central del muro oeste del castillo arzobispal de Santorcaz. El mismo todavía es apreciable en una fotografía antigua realizada en torno al año 1900, conservada en el Archivo Regional de la Comunidad de Madrid.

141 La planta de la misma todavía es apreciable en una imagen aérea de la población tomada en los años cuarenta del pasado siglo, conservada en el Instituto Geográfico Nacional.

${ }^{142}$ Recordemos los acontecimientos ocurridos en 1242.
} 
la mitra como Belinchón ${ }^{143}$ o Fuentes de la Alcarria $^{144}$. También parecen ser coetáneas las fortificaciones de Melgar y Cabañas, aunque de nuevo la ausencia documental ${ }^{145}$ nos imposibilite trazar hipótesis sólidas al respecto. En relación con la primera podemos destacar la existencia de un documento datado en $1286^{146}$ en el que se menciona un «castel viejo» en el entorno de la aldea. Dicha afirmación puede llevarnos a pensar en la existencia de un castillo de construcción más reciente, erigido por los prelados con el fin de controlar las vías de comunicación y recursos presentes en el valle del Cedrón. La finalidad de la torre ubicada en Cabañas, por contra, resulta menos evidente. La misma se encontraba ya erigida en el año $1318^{147}$.

La creciente hostilidad mostrada por el concejo toledano, ya en la primera mitad del siglo XIV, trajo consigo la ejecución de una serie de obras de gran envergadura. Éstas se encontrarían dirigidas ante todo a evitar una pérdida total de la villa ante un posible ataque por parte de los toledanos. Las denominadas torres norte y sur, ambas cuadrangulares y construidas con mampostería y sillares, siendo estos últimos reservados para el refuerzo de las esquinas, tendrían su origen en este período. La primera podría ser calificada como albarrana ${ }^{148}$ mientras que la segunda, dotada de ladroneras, constituiría el único vestigio del antiguo alcázar ${ }^{149}$ o palacio arzobispal de Yepes, posiblemente edificado por Juan de Aragón como ya se ha señalado. Posteriormente dicha torre y la denominada central sufrirían una gran reforma, siendo dotadas de acceso al adarve y de una nueva caja de escaleras. Las obras mencionadas pudieron haber tenido lugar en dos fases distintas dada la diferente medida de los "cajones" de mampostería señalada por María Magdalena Merlos ${ }^{150}$. La pervivencia del escudo de Pedro Tenorio en el cierre

\footnotetext{
${ }^{143}$ En el fuero otorgado a la población en 1253 por Sancho de Castilla, electo arzobispo, queda establecido lo siguiente: «la parte de las calonnas del conceio que sea para la lauor del castiello». HeRNÁNDEZ, Los Cartularios..., doc. $\mathrm{n}^{\mathrm{o}} 491$.

144 La fortificación debió de erigirse en una fecha comprendida entre la entrega de la población a Sancho de Castilla (1255) y la mención que del alcaide del lugar se hace en el fuero otorgado por Gonzalo Gudiel (c. 1299). VÁzquez de Parga, "Fuero de Fuentes...", p. 363.

145 De ellas se aporta en 1435 información reseñable. Benito RuAno, "Visita de las villas...”, pp. 85-86

146 El castillo de Melgar edificado en el siglo XIII, del que se conservan hoy sus ruinas, también pudo ser levantado sobre los restos de una fortificación islámica anterior. MAROTO GARRIDO y MARTín MonTES, Villasequilla..., p. 327.

147 «et en Cabanas de Yepes un corral, çerca la torre, con dos casas». ACT O.10.B.1.8. En 1435 la torre se encontraba ya caída. Benito Ruano, "Visita de las villas...", pp. 85-86.

148 Al menos ello se advierte de la orientación y posición de las torres próximas, la denominada central y la ubicada a un lado de la calle de la Luna. El castillo de Santorcaz también contaba con una torre albarrana de gran envergadura.

149 Dicha vinculación parece confirmarse por un documento del año 1494. En ese año Tomás Gaitán vende al concejo de Yepes un mesón, cercano a la plaza, colindante con dos calles: la de la Sinagoga y "la que va de la plaza al alcázar". La primera sigue existiendo hoy día mientras que la segunda seguramente se corresponda con la actual calle Ancha, la cual une la plaza mayor con la citada torre sur. RICO SÁEzBravo, "Las juderías... ", pp. 209-219. En la misma todavía se puede apreciar el arranque de un antiguo muro perpendicular a la trayectoria del recinto amurallado.

150 Merlos Romero, Yepes en la Edad Media..., p. 122.
} 
de una de las bóvedas de la torre central puede servirnos de cara a identificar al artífice de una de estas fases ${ }^{151}$.

En cuanto al segundo recinto amurallado, únicamente podemos asociar el inicio de su construcción a la recuperación de la jurisdicción por parte del arzobispo Tenorio en 1384. Su inexistencia previa parece ponerse de manifiesto con motivo de la facilidad con la que, a la muerte de Gómez Manrique, la comitiva toledana logró llegar hasta la iglesia de San Benito, situada extramuros del recinto del siglo XIII' ${ }^{152}$.

\section{Conclusiones}

El señorío arzobispal adoleció desde su inicio de una serie de problemas que, con el tiempo, llegarían a ocasionar su momentánea desaparición. El primero fue la elevada presencia dentro del mismo de un considerable número de propiedades en poder de personas avecindadas en Toledo. El origen de las mismas puede remontarse a la entrega de Yepes por parte del rey a la collación toledana de San Nicolás. El segundo afecta a la adquisición de la todavía aldea por parte de Rodrigo Jiménez de Rada, quien se consideraría señor de la misma sin poseer la totalidad de las partes en que se dividía su propiedad. De igual modo, la donación regia obtenida tras la realización de las primeras compras sólo justificaría la recaudación del impuesto del mortuorio, no la conversión de la aldea concejil en villa arzobispal, con la consiguiente transformación del enclave en un señorío banal. Como consecuencia de ello no es de extrañar que gran parte de los vecinos de Toledo con propiedades en Yepes consideraran que pudieran quedar exentos, al igual que sus trabajadores, de la jurisdicción del prelado.

Se han podido constatar extensos períodos en los que se produce la citada elusión jurisdiccional. El primero abarcaría desde el año 1223 hasta 1242. El segundo, en base a la documentación conservada, tendría su inicio en una fecha cercana a 1332 y finalizaría en 1368. El último, en parte una continuación del anterior, incluiría los años comprendidos entre 1375 y 1389. El origen y conclusión de los mismos no fue análogo, influyendo en ello el contexto político y económico del momento. Las situaciones de inestabilidad constatadas en el siglo XIII deben de ser entendidas como una respuesta consecuente ante el cambio de titularidad experimentado en la propiedad de la aldea. En cambio, durante el siglo XIV la pugna por la jurisdicción entre los toledanos y la

\footnotetext{
151 Aunque recurrentemente se haya insistido en vincular dicho escudo, que muestra un león rampante, al rey Alfonso VIII. Ejemplo de ello: Merlos Romero, Yepes en la Edad Media..., p. 146; PAvón Maldonado, "Miscelánea de arte...", p. 222.

${ }^{152}$ Más concluyente podría haber resultado la lectura de un documento, hoy desaparecido, existente en el Archivo Parroquial de Yepes. En él Pedro Tenorio establecía el pago de un tributo a sus vasallos para levantar las murallas. Trillo SiABA, Breve historia..., p. 19. Dicho dato ha llevado a otros autores a vincular el segundo recinto con dicho arzobispo. Merlos Romero, Yepes en la Edad Media..., p. 108. En una fecha cercana, el mismo prelado emitió desde Yepes, «nuestra villa», una provisión ordenando al lugarteniente del deán, arcedianos, canónigos, racioneros, clérigos, beatos, viudas y vecinos de Toledo en general, contribuir a reparar los muros de Toledo bajo amenaza de excomunión. AMT, cajón 4. Leg. 1, nº 3 .
} 
sede primada fue constante. Las sucesivas crisis derivadas de la minoría de edad del rey Alfonso XI, la Peste y las guerras, sin duda contribuyeron a ello, ocasionando que el concejo toledano abandonara su política proteccionista en favor de la reivindicación directa de algunas de las tierras de la Iglesia.

Como se ha señalado en el presente artículo los sucesivos titulares de la sede primada hicieron frente a la situación de modo diverso, bien a través de la concesión de mercedes a sus vasallos (Gonzalo Díaz Palomeque), la fortificación de la villa (posiblemente Juan de Aragón y Pedro Tenorio), la elaboración de concordias (Gil de Albornoz), o el recurso a la justicia regia (Jimeno de Luna, Gómez Manrique y Pedro Tenorio).

La acción de la monarquía respecto al enfrentamiento en torno a Yepes fue ambigua, únicamente Juan I parece dictar una sentencia firme favorable a Pedro Tenorio. Recordemos que Enrique II incumpliría su palabra otorgando Yepes al concejo de Toledo tras la muerte de su antiguo canciller. En cuanto a la sentencia pronunciada por Alfonso XI, la lectura de la misma y la elaboración de la concordia de 1346, nos indican que no fue definitiva.

Por último, el proceso de consolidación del señorío eclesiástico llevado a cabo en la segunda mitad del siglo XIII no debe de considerarse fallido. La fortificación de la villa y su alfoz, la expansión de los términos y la compra de propiedades en poder de personas avecindadas en Toledo sin duda ayudaron a aminorar los problemas que tendrían lugar unas décadas más tarde. 
Figura 1.

Mapa del señorío arzobispal de Yepes a principios del siglo XIV

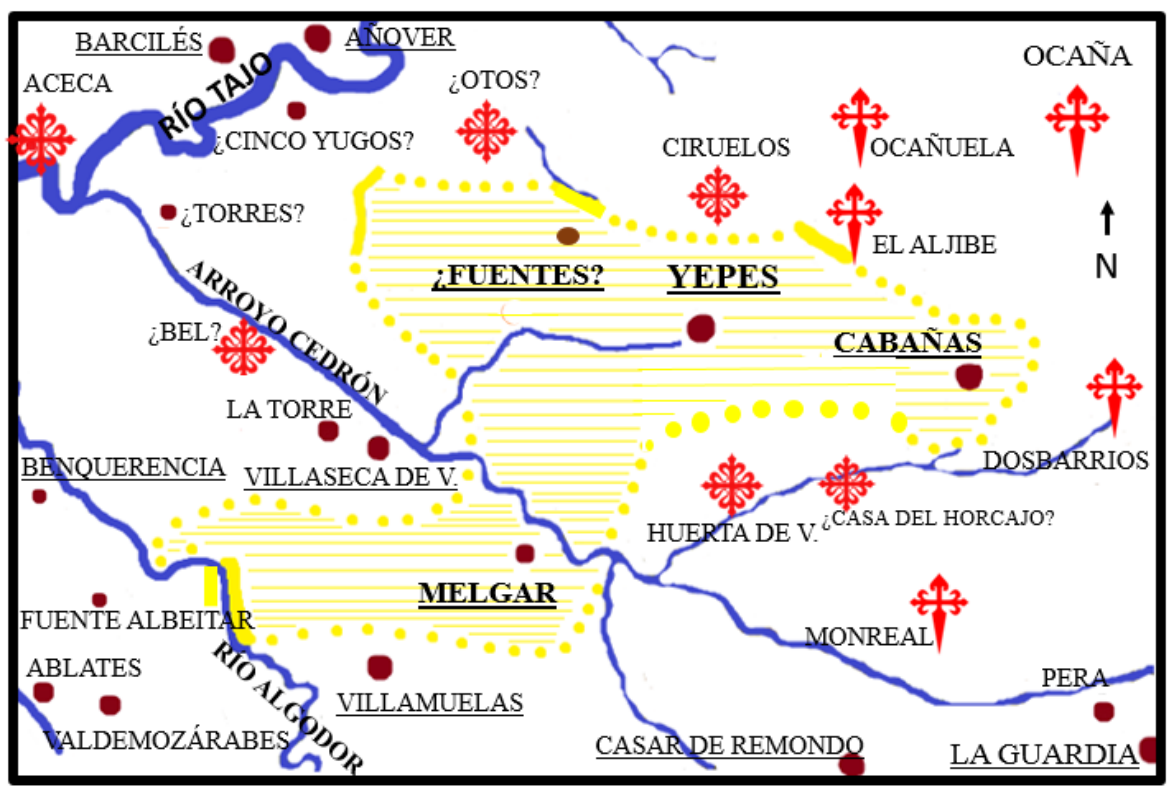

Fronteras del señorío constatadas documentalmente:

Fronteras probables:

Espacio ocupado por el señorío:

Villas y aldeas pertenecientes a la sede primada: $\quad \underline{\text { La Guardia }}$

Villas y aldeas cuya ubicación exacta se desconoce: ¿ ¿Torres?

Posesiones de la Orden de Calatrava:

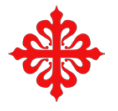

Posesiones de la Orden de Santiago:

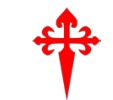




\section{Bibliografía}

Asenjo GonzÁlez, María, "Ciudades y hermandades en la Corona de Castilla. Aproximación sociopolítica", Anuario de Estudios Medievales, 27-1 (1997), pp. 103-146.

Barrero García, Ana María y Alonso Martín, María Luz, Textos de derecho local español en la Edad Media: catálogo de fueros y costums municipales, CSIC, Madrid, 1989.

Bartolomé Herrero, Bonifacio, "El señorío temporal de los obispos de Segovia en la Edad Media”, Anuario de Estudios Medievales, 26-1 (1996), pp. 191-220.

Benito Ruano, Eloy, "Visita de las villas y lugares del Arzobispado de Toledo (1435)", Anales Toledanos, 5 (1971), pp. 77-103.

Cepeda AdÁn, José, "Repoblación en la zona del Tajo. Estudios y Documentos", Cuadernos de Historia Moderna. Universidad de Valladolid, 7 (1955), pp. 1-42.

Díaz Fernández, Antonio José, “Aceca, de castillo a palacio”, Anales Toledanos, 27 (1990), pp. 81-96.

DíAz IBÁÑEz, Jorge, Iglesia, sociedad y poder en Castilla. El obispado de Cuenca en la Edad Media (siglos XII-XV), Alfonsípolis, Cuenca, 2003.

Fita Colomé, Fidel, "La Guardia, villa del partido de Lillo, provincia de Toledo. Datos históricos", BRAH, 11 (1887), pp. 374-431.

Flórez, Enrique, España Sagrada, Imprenta de Antonio Marín, Madrid, 1767, t. XXIII.

García De Valdeavellano, Luis, "Carta de Hermandad entre los concejos de la Extremadura castellana y del arzobispado de Toledo", Rev. Portuguesa de Historia, 12 (1969), pp. 69-76.

García Luján, José Antonio, Privilegios reales de la Catedral de Toledo (1086-1462): formación del patrimonio de la S.I.C.P. a través de las donaciones reales, Caja de Ahorros Provincial de Toledo, Toledo, 1982.

García Moreno, Luis, "El término «sors» y otros relacionados en el Liber Iudicum: de nuevo el problema de la división de las tierras entre godos y provinciales", Anuario de historia del derecho español, 53 (1983), pp. 138-177.

GonzÁlez GonzÁlez, Julio, Repoblación de Castilla la Nueva, UCM, Madrid, 1975, 2 vols.

González Palencia, Ángel, Los mozárabes de Toledo en los siglos XII y XIII, Instituto Valencia de Don Juan, Madrid, 1926-1930, 4 vols.

GonzÁlvez Ruiz, Ramón, Hombres y libros de Toledo, Fundación Ramón Areces, Madrid, 1997.

Gorosterratzu Jaunarena, Javier, Don Rodrigo Jiménez de Rada, gran estadista, escritor y prelado, Imprenta de la viuda de T. Bescansa, Pamplona, 1925.

Grassotti, Hilda, Don Rodrigo Ximénez de Rada, gran señor y hombre de negocios en la Castilla del siglo XIII, Universidad de Buenos Aires, Buenos Aires, 1973. 
Grassotti, Hilda, Estudios medievales españoles, Fundación universitaria española, Madrid, 1981.

Grassotti, Hilda, “Otra vez sobre el señorío de Illescas", Estudios de historia de España, 1 (1988), pp. 39-70.

Hernández, Francisco Javier, Los Cartularios de Toledo: catálogo documental, Fundación Ramón Areces, Madrid, 1996.

IzQuierdo Benito, Ricardo, "Conflictos entre los poderes temporal y eclesiástico en las ciudades medievales: el caso de Toledo en 1390”, En la España medieval, 7 (1985), pp. 1.081-1.104.

IzQUiERdo Benito, Ricardo, El patrimonio del cabildo de la catedral de Toledo durante el siglo XIV, Caja de Ahorro Provincial de Toledo, Toledo, 1980.

IzQuierdo Benito, Ricardo, Privilegios Reales otorgados a Toledo durante la Edad Media (1101-1494), Diputación Provincial de Toledo, Toledo, 1990.

JimÉnez de Gregorio, Fernando, "La comarca de la Mesa de Ocaña”, Serie VI. Temas Toledanos, 83-84 (1996), pp. 1-93.

Ladero Quesada, Miguel Ángel, "El sistema impositivo en Castilla y León. Siglos XXIII", Jornadas sobre documentación jurídico-administrativa, económico-financiera y judicial del reino castellano-leonés. Siglos X-XIII, Ángel Riesco Terrero (coord.), Universidad Complutense, Madrid, 2002, pp. 283-302

León Tello, Pilar, Judíos de Toledo, CISC, Madrid, 1979.

Lomax, Derek, "El arzobispo Rodrigo y la Orden de Santiago", Hispania, 76 (1959), pp. 323-365.

LóPez de Ayala, Jerónimo, Contribuciones e impuestos en León y Catilla durante la Edad Media, Imprenta del Asilo de Huérfanos del Sagrado Corazón de Jesús, Madrid, 1896. Mansilla, Demetrio, La documentación pontificia de Honorio III (1216-1227), Instituto Español de Historia Eclesiástica, Roma, 1965.

Maroto Garrido, Mariano, y Martín Montes, Esperanza, Villasequilla. Memorias de su Historia, LEDORIA, Toledo, 2017.

Merlos Romero, María Magdalena, “Arquitectura militar en las villas medievales del Arzobispo de Toledo: función y significado", Espacio, tiempo y forma. Serie VII, Historia del arte, 13 (2000), pp. 27-50.

Merlos Romero, María Magdalena, Yepes en la Edad Media: población, urbanismo, arquitectura, Diputación de Toledo, Toledo, 1998.

MolÉnat, Jean-Pierre, Campagnes et monts de Tolède du XIIe au XVe siècle, Casa de Velázquez, Madrid, 1997.

Muñoz Ruano, Juan, Construcciones histórico-militares en la línea estratégica del Tajo, UCM, Madrid, 2003.

Nieto Soria, José Manuel, “La relación de poderes en un señorío eclesiástico de ámbito urbano: Palencia 1280-1305”, En la España Medieval, 6 (1985), pp. 625-640. 
Nieto SoRia, José Manuel, Iglesia y poder real en Castilla: el episcopado, 1250-1350, UCM, Madrid, 1988.

Nieto Soria, José Manuel, Las relaciones monarquía-episcopado castellano como sistema de poder (1252-1312), UCM, Madrid, 1982.

Pavón Maldonado, Basilio, "Miscelánea de arte hispanomusulmán", Boletín de la Asociación Española de Orientalistas, 15 (1979), pp. 189-222.

Rico Sáez-Bravo, Remedios, "Las juderías de Ocaña y Yepes", El legado material hispanojudio, Ana María López Álvarez y Ricardo Izquierdo Benito (coords.), UCLM, Cuenca, 1998, pp. 209-219.

Rivera Recio, Juan Francisco, "Patrimonio y señorío de Santa María de Toledo desde el 1086 hasta el 1208", Anales toledanos, 9 (1974), pp. 117-182.

Rodríguez-Picavea Matilla, Enrique, "Documentos para el estudio de la Orden de Calatrava en la meseta meridional castellana (1102-1302)", Cuadernos de Historia Medieval, Secc. Colecciones Documentales, 2 (1999), pp. 1-326.

Trillo Siaba, Tirso, "Breve historia de Yepes", Serie VI. Temas Toledanos, 19 (1982), pp. 1-63.

VÁzquez de Parga, Luis, "Fuero de Fuentes de la Alcarria", Anuario de historia del derecho español, 18 (1947), pp. 348-398. 